\title{
To bridge or not to bridge: The role of sulfuric acid in the Beckmann rearrangement
}

\author{
Chester R. Lin, ${ }^{a}$ Li-Juan $\mathrm{Yu},{ }^{b}$ Shuhua $\mathrm{Li},{ }^{a}$ and Amir Karton ${ }^{b, *}$ \\ ${ }^{a}$ School of Chemistry and Chemical Engineering, Key Laboratory of Mesoscopic Chemistry of \\ Ministry of Education, Institute of Theoretical and Computational Chemistry, Nanjing \\ University, Nanjing, 210023, P. R. China \\ ${ }^{b}$ School of Chemistry and Biochemistry, The University of Western Australia, Perth, WA 6009, \\ Australia
}

\begin{abstract}
A B S T RA C T
Based on ab initio calculations using the Gaussian-4 method, we propose a new catalytic mechanism for the Beckmann rearrangement in concentrated $\mathrm{H}_{2} \mathrm{SO}_{4}$. Our calculations suggest that $\mathrm{H}_{2} \mathrm{SO}_{4}$ catalyzes the 1,2-proton-shift step via a cyclic transition structure, in which $\mathrm{H}_{2} \mathrm{SO}_{4}$ acts as a proton-transfer bridge. The reaction barrier for this mechanism is lower by $48.1 \mathrm{~kJ} / \mathrm{mol}$ than the barrier for the previously suggested catalytic mechanism, which involves a strained 3memberd-ring transition structure. According to the previous mechanism the 1,2-proton shift has the highest activation energy, while in the revised mechanism the highest activation energy is obtained for the ensuing rearrangement/dehydration step.
\end{abstract}

Keywords: Beckmann rearrangement, $\mathrm{H}_{2} \mathrm{SO}_{4}$ catalyst, $\mathrm{CCSD}(\mathrm{T})$, G4 theory.

\section{Citation:}

C. R. Lin, L.-J. Yu, S. Li and A. Karton. To bridge or not to bridge: The role of sulfuric acid in the Beckmann rearrangement. Chemical Physics Letters, 659, 100-104 (2016). http://dx.doi.org/10.1016/j.cplett.2016.07.018 


\section{Introduction}

The Beckmann rearrangement (BR) reaction is an important organic reaction in which an oxime is converted into an amide under acidic conditions (Figure 1). It was discovered by Ernst Otto Beckmann in 1886, ${ }^{1}$ and has become a powerful tool in organic synthesis. ${ }^{2-4}$ For example, it is a key step in the conversion of cyclohexanone oxime into $\varepsilon$-caprolactam - a precursor of the Nylon-6 polymer. ${ }^{5,6}$ The BR reaction is also utilized in an environmentally friendly synthesis of paracetamol, namely in the conversion of $p$-hydroxyacetophenone oxime to the amide form paracetamol. ${ }^{7}$ The BR reaction is generally carried out in a strong Brønsted acid such as condensed sulfuric acid. ${ }^{4}$
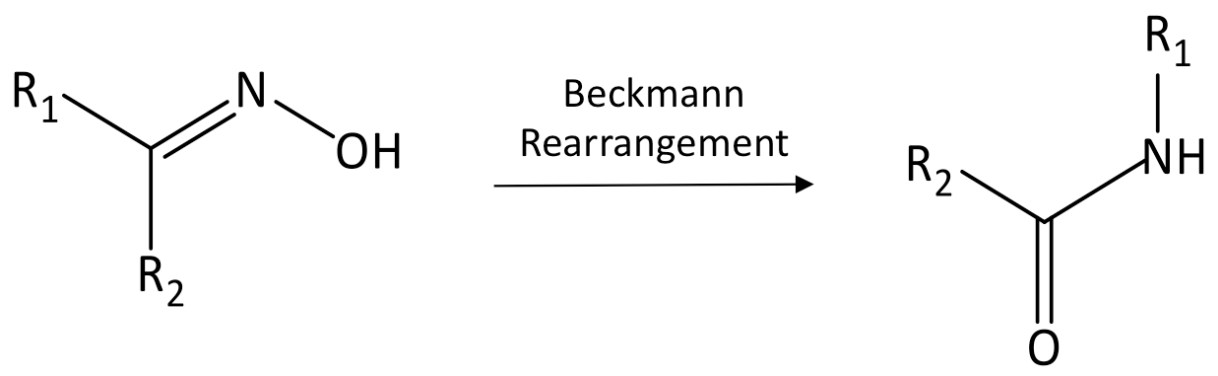

Figure 1. Beckmann rearrangement transforms an oxime (left) to an $N$-substituted amide (right).

There have been several computational investigations of the molecular mechanism of the BR reaction in the gas-phase, ${ }^{8,9}$ water, ${ }^{10,11}$ formic acid, ${ }^{10}$ and acetic acid. ${ }^{12}$ These investigations have established a stepwise mechanism for the BR reaction of an oxime substrate (Figure 2). In a concentrated acidic environment, the process begins with the $N$-protonated oxime (1). In the first step a proton-transfer converts the $N$-protonated oxime into an energetically less stable $O$ protonated intermediate (2). ${ }^{10-12}$ The proton transfer is followed by a dehydration and rearrangement step to form the protonated $N$-substituted nitrile cation (3). In this dehydration/rearrangement step the R-group trans to the leaving $\mathrm{H}_{2} \mathrm{O}$ group migrates from $\mathrm{C}$ to $\mathrm{N}$ (Figure 2). This step is followed by a nucleophilic attack by water on the $\alpha$-carbon and a consequent proton transfer to form the final protonated amide product (4). Alternatively, the last step may be viewed as a nucleophilic addition of a water molecule across the triple $\mathrm{C} \equiv \mathrm{N}$ bond in the nitrile cation $(\mathbf{3})$. 


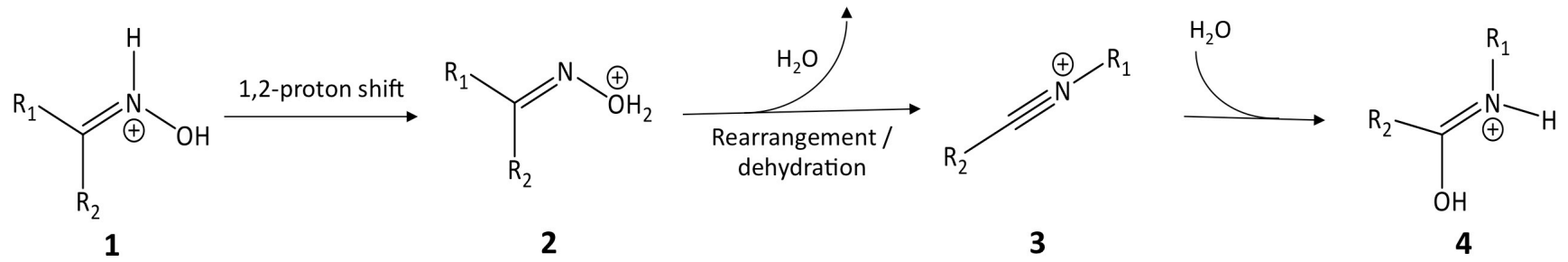

Figure 2. Overview of mechanism of the Beckmann rearrangement.

The gas-phase mechanism for the BR reaction with a formaldehyde oxime substrate has been previously studied at the MP4/6-311++G(d,p) level of theory. ${ }^{8,9}$ It was found that the $N$ protonated form of formaldehyde oxime (1) is more stable than the $O$-protonated form (2) by 77 $\mathrm{kJ} \mathrm{mol}^{-1}$. It was also found that the reaction barrier heights for the 1,2-proton shift $(\mathbf{1} \rightarrow \mathbf{2}$, Figure 2) and for the consequent dehydration/rearrangement $(\mathbf{2} \rightarrow \mathbf{3})$ steps are 225 and $121 \mathrm{~kJ}$ $\mathrm{mol}^{-1}$, respectively, relative to the starting material (1). Thus, it was concluded that in the gasphase the 1,2-proton-shift is the rate-determining step (RDS). In a following study the mechanism for the BR reaction was investigated in aqueous solution using the polarizable continuum model $(\mathrm{PCM})^{13}$ in conjunction with an explicit $\mathrm{H}_{2} \mathrm{SO}_{4}$ catalyst. ${ }^{11}$ This study showed that implicit solvation interactions have only a small effect on both the energetic and geometric parameters of the reaction pathway. However, electrostatic interactions with the explicit $\mathrm{H}_{2} \mathrm{SO}_{4}$ catalyst significantly reduce the reaction barrier for the 1,2-proton-shift step. In particular, at the MP2/6-311G(d,p) level of theory, the reaction barrier is decreased by $115 \mathrm{~kJ} \mathrm{~mol}^{-1}$ with respect to the reaction barrier in the gas-phase. In this $\mathrm{H}_{2} \mathrm{SO}_{4}$-catalyzed transition structure (TS) the migrating proton is strongly coordinated to one of the oxygen atoms of the sulfuric acid. ${ }^{11}$ This TS is illustrated schematically in Figure 3a. 


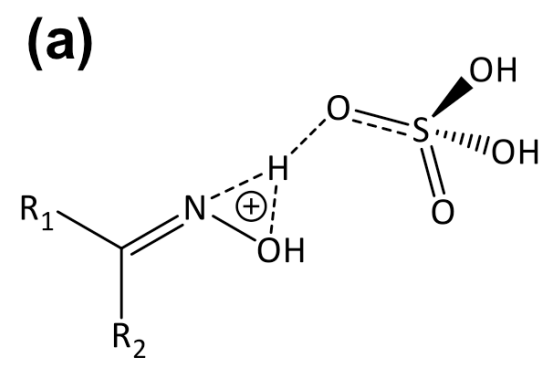

TS1 3-membered

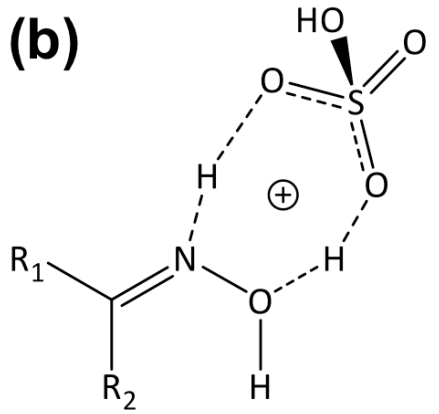

TS1 7-membered

Figure 3. A schematic representation of the transition structures for the 1,2-proton-shift step catalyzed by $\mathrm{H}_{2} \mathrm{SO}_{4}$, where (a) $\mathrm{H}_{2} \mathrm{SO}_{4}$ does not act as a proton bridge, and (b) $\mathrm{H}_{2} \mathrm{SO}_{4}$ acts as a proton bridge.

It has been recently found that sulfuric acid can effectively catalyze 1,2- and 1,3-protonshifts via a cyclic TS in which the $\mathrm{H}_{2} \mathrm{SO}_{4}$ catalyst serves as a proton-transfer bridge between the neighboring 1,2 or 1,3 atoms. ${ }^{14,15}$ In these catalyzed TSs a double proton shift between the catalyst and the substrate lowers the energy of the TS by reducing the strain energy associated with the strained cyclic ring created between the 1,2 or 1,3 heavy-atoms and the migrating proton. ${ }^{14-16}$ Figure $3 \mathrm{~b}$ illustrates the reduction in strain energy for the 1,2-proton shift in the BR reaction. In the catalytic mechanism which was previously proposed for the BR reaction the cyclic TS involves a strained three-membered ring (Figure 3a, this TS will be denoted as $\mathrm{TS}_{3-}$ membered), ${ }^{11}$ whereas in the catalytic mechanism suggested in references 14 and 15 this threemembered ring becomes a much less strained seven-membered-ring (Figure 3b, this TS will be denoted as $\mathrm{TS}_{7 \text {-membered) }}$.

In the present work we use the high-level ab initio G4 procedure ${ }^{17}$ to study these two catalytic mechanisms in the context of the entire Gibbs-free energy surface for the BR reaction (steps 1-4, Figure 2). Our G4 results for the 1,2-proton shift via TS13-membered (Figure 3a) are in good agreement with the MP2/6-311G(d,p) results of the previous theoretical studies. ${ }^{10,11}$ That is, the 1,2-proton shift is the step with the highest activation Gibbs-free energy in both the gas-phase and in sulfuric acid. However, in the competing 7-membered-ring TS (Figure 3b) the sulfuric acid catalyst stabilizes the TS to a greater extent, and as a result this step is no longer the highest 
activation energy step. In this mechanism, the rearrangement/dehydration step (step 2, Figure 2) becomes the step with the highest Gibbs-free activation energy. We note that kinetic isotope effect experiments of BR reaction of substituted acetophenone oximes in concentrated sulfuric acid also suggest that the rearrangement/dehydration step is the rate-determining step. ${ }^{18}$

\section{Computational details}

The high-level composite Gaussian-4 (G4) theory was used in order to explore the Gibbsfree energy surface at $298 \mathrm{~K}$ for the BR reaction. ${ }^{17}$ The G4 composite protocol is an efficient composite procedure for approximating the $\operatorname{CCSD}(\mathrm{T})$ (coupled cluster energy with singles, doubles, and quasiperturbative triple excitations) energy in conjunction with a large triple- $\zeta-$ quality basis set. ${ }^{19-21}$ This protocol is widely used for the calculation of thermochemical and kinetic properties (for a recent review of the $\mathrm{G} n$ methods see reference 19). G4 theory has been found to produce thermochemical properties (such as reaction energies, bond dissociation energies, and enthalpies of formation) with a mean absolute deviation of $3.4 \mathrm{~kJ} \mathrm{~mol}^{-1}$ from the 454 experimental energies of the G3/05 test set. ${ }^{22}$ It has also been found that G4 shows a similarly good performance for reaction barrier heights. ${ }^{23-26}$

The geometries of all structures have been optimized at the B3LYP/6-31G(2df,p) level of theory as prescribed in the G4 procedure. ${ }^{17}$ Harmonic vibrational analyses have been performed to confirm each stationary point as either an equilibrium structure (i.e., all real frequencies) or a transition structure (i.e., with one imaginary frequency). The connectivities of the local minima and saddle points were confirmed by performing intrinsic reaction coordinate calculations. ${ }^{27,28}$ Bulk solvent effects of concentrated sulfuric acid have been included using the charge-densitybased SMD continuum solvation model at the M05-2X/6-31+G** level of theory as recommended in reference 29. The combination of the G4 gas-phase energies with the SMD solvation corrections is denoted by $\mathrm{SMD}\left(\mathrm{H}_{2} \mathrm{SO}_{4}\right)$-G4. All the calculations were carried out using the Gaussian 09 program suite. ${ }^{30}$

\section{Results and discussion}

High-level $a b$ initio calculations using the G4 composite procedure were performed in order to explore the Gibbs-free energy surface at $298 \mathrm{~K}$ for the uncatalyzed and $\mathrm{H}_{2} \mathrm{SO}_{4}$-catalyzed $B R$ reaction. In many synthetic processes that involve the $B R$ reaction the $R_{1}$ and $R_{2}$ groups of 
the oxime substrate are hydrocarbon substituents (Figure 1). For reasons of computational cost, the oxime substrate is chosen as acetone oxime (i.e., $\mathrm{R}_{1}=\mathrm{R}_{2}=$ Me, Figure 1). In Section 3.1 we discuss the Gibbs-free energy surface for the uncatalyzed BR reaction in concentrated $\mathrm{H}_{2} \mathrm{SO}_{4}$ solution. In Section 3.2 we consider the two possible catalytic mechanisms, in which the 1,2proton-shift step proceeds via either $\mathrm{TS}_{3} 1_{3 \text {-membered }}$ or $\mathrm{TS}_{7 \text {-membered }}$ (Figure 3 ).

\subsection{The uncatalyzed $B R$ reaction}

The optimized structures located along the reaction profile for the uncatalyzed BR reaction are shown in Figure 4, whilst the Gibbs-free energy surface is shown in Figure 5. In the first step the $N$-protonated acetone oxime (Reac) undergoes a 1,2-proton shift to form the $O$ protonated acetone oxime (Int1). The transition structure for this step involves a highly strained 3-membered ring. This is evident, for example, from $\angle \mathrm{ONH}$ and $\angle \mathrm{NOH}$ angles of $49.6^{\circ}$ and $47.5^{\circ}$, respectively (TS1, Figure 4). For comparison, in the reactant (Reac) the $\angle \mathrm{ONH}$ angle is $115.4^{\circ}$. Accordingly, the reaction barrier for this step is very high, namely $\Delta G^{\ddagger}{ }_{298}$ (TS1) $=245.7$ $\mathrm{kJ} \mathrm{mol}^{-1}$. This barrier is in good agreement with the barrier of $234 \mathrm{~kJ} \mathrm{~mol}^{-1}$ reported previously for a related system at a lower level of theory (i.e., MP2/6-311G(d,p)). ${ }^{11}$ The ensuing $O$ protonated intermediate (Int1) constitutes the starting point for the rearrangement/dehydration step (Figures 2 and 5). ${ }^{31}$ The rearrangement/dehydration step involves a migration of the methyl group from $\mathrm{C}$ to $\mathrm{N}$ with a concomitant elimination of water to form the $\mathrm{N}$-methylated acetonitrile cation (Int2). The barrier for this step is about half of that for the 1,2-proton shift, namely $\Delta G^{\ddagger}{ }_{298}(\mathbf{T S 2})=115.9 \mathrm{~kJ} \mathrm{~mol}^{-1}$, relative to the reactant (Reac). We note that Int2 is a rather stable

reaction intermediate, which is lower in energy than the reactant by $137.0 \mathrm{~kJ} \mathrm{~mol}^{-1}$. The last step of the reaction involves a nucleophilic attack of a water molecule on the electrophilic carbon of Int2 and a concomitant proton-shift from the oxygen to the nitrogen to form a protonated $N$ methyl acetyl amide (Prod, Figure 4). Two important features of the Gibbs-free energy surface for the uncatalyzed $\mathrm{BR}$ reaction are:

$>$ The initial 1,2-proton transfer is clearly the RDS for the overall process: TS1 is higher by 128.7 and $175.3 \mathrm{~kJ} \mathrm{~mol}^{-1}$ than TS2 and TS3, respectively.

$>$ The overall process is highly exothermic. The final product is lower in energy than the reactant by $171.9 \mathrm{~kJ} \mathrm{~mol}^{-1}$. 

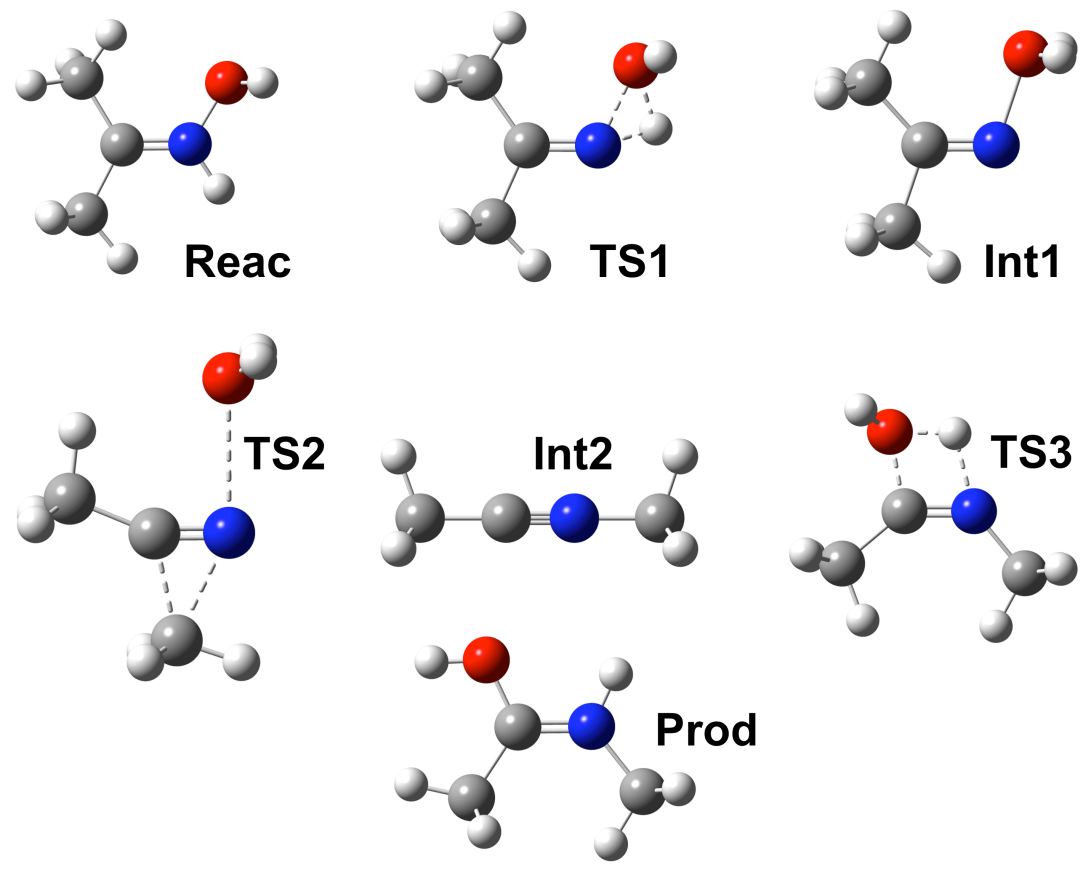

Figure 4. $\mathrm{B} 3 \mathrm{LYP} / 6-31 \mathrm{G}(2 \mathrm{df}, \mathrm{p})$ optimized local minima and transition structures for the uncatalyzed BR reaction. The atomic colour scheme is as follows: white, $\mathrm{H}$; grey, C; blue, N; red, O.

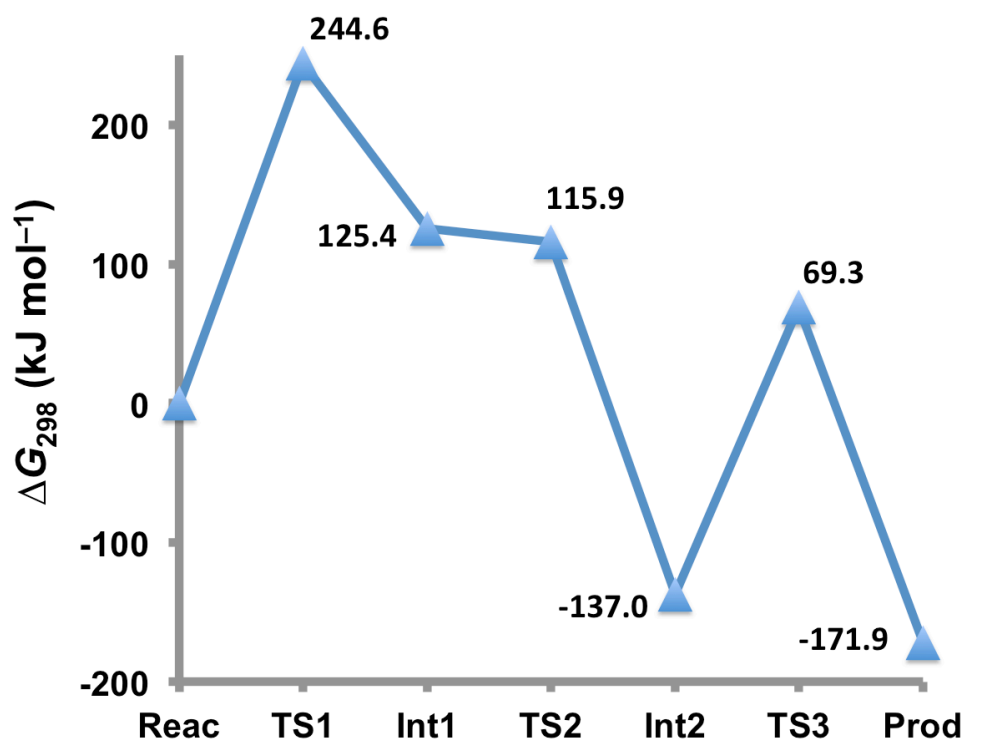

Figure 5. Gibbs-free energy surface for the uncatalyzed BR reaction $\left(\mathrm{SMD}\left(\mathrm{H}_{2} \mathrm{SO}_{4}\right)-\mathrm{G} 4, \mathrm{~kJ} \mathrm{~mol}^{-}\right.$ $\left.{ }^{1}\right)$. The local-minima and transition structures are shown in Figure 4. 


\subsection{The $\mathrm{BR}$ reaction catalyzed by an $\mathrm{H}_{2} \mathrm{SO}_{4}$ catalyst}

In subsection 3.1 we have shown that the 1,2-proton shift is the RDS for the uncatalyzed BR reaction. These results are consistent with previous theoretical investigations. ${ }^{10,11}$ We now explore two possible catalytic mechanisms in which the RDS is catalyzed by an explicit $\mathrm{H}_{2} \mathrm{SO}_{4}$ catalyst. Figure 6 shows the reactant complex $(\mathbf{R C})$, catalyzed transition structures $\left(\mathbf{T S 1}_{3 \text {-membered }}\right.$ and $\mathrm{TS1}_{7 \text {-membered }}$, and the intermediate complex formed between Int1 and the $\mathrm{H}_{2} \mathrm{SO}_{4}$ catalyst. The reaction profiles for the uncatalyzed and catalyzed steps are shown in Figure 7.
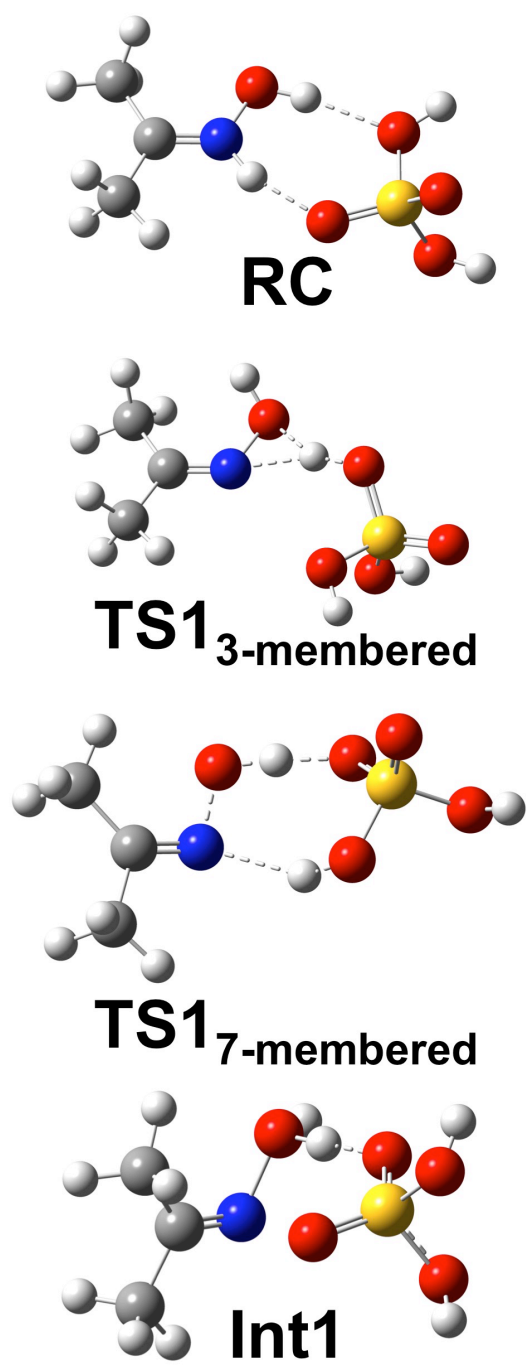

Figure 6. Optimized local minima and transition structures for the catalyzed 1,2-proton shift in the $\mathrm{BR}$ reaction. The atomic colour scheme is as follows: white, $\mathrm{H}$; grey, $\mathrm{C}$; blue, N; red, O; yellow, $\mathrm{S}$. 


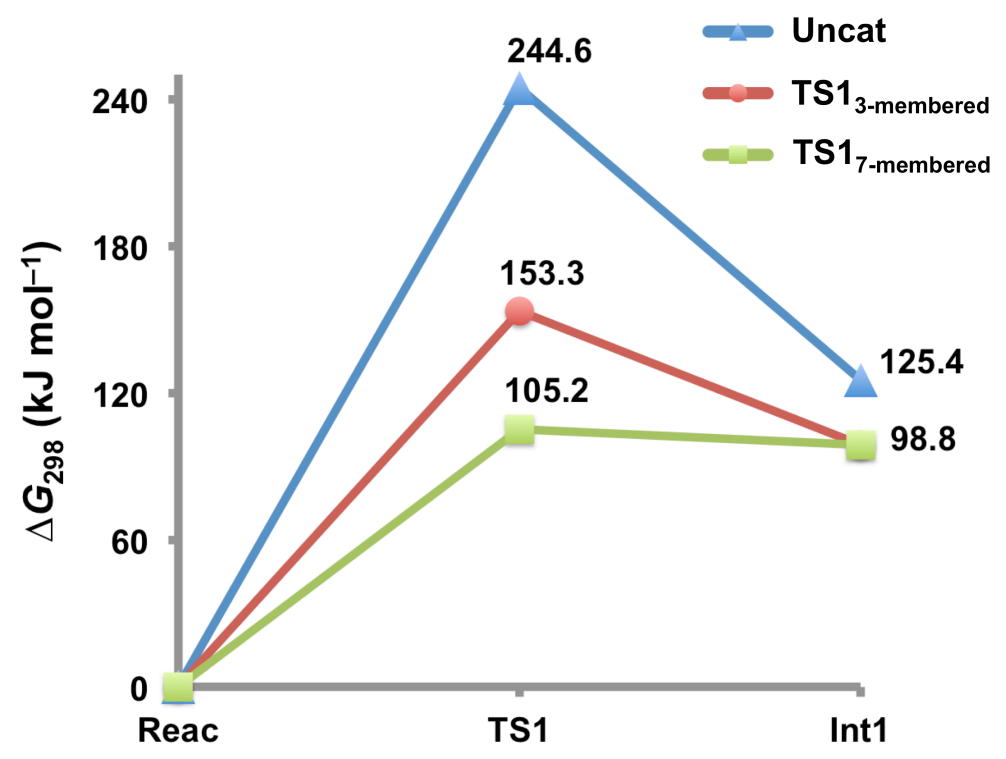

Figure 7. Gibbs-free energy surface at $298 \mathrm{~K}$ for the catalyzed 1,2-proton shift in the BR reaction $\left(\mathrm{SMD}\left(\mathrm{H}_{2} \mathrm{SO}_{4}\right)-\mathrm{G} 4, \mathrm{~kJ} \mathrm{~mol}^{-1}\right)$. The local-minima and transition structures are shown in Figure 6. For the sake of clarity, the reaction profile for the uncatalyzed reaction from Figure 5 is shown here as well (blue curve).

Let us begin with the previously proposed catalytic mechanism, ${ }^{11}$ in which the migrating proton is strongly coordinated to one of the oxygen atoms of the sulfuric acid. The catalyzed transition structure ( $\mathbf{T S 1}_{3 \text {-membered }}$ ) is shown in Figure 6. In this TS the migrating proton is essentially bound to the oxygen of the sulfuric acid catalyst. ${ }^{11}$ This is indicated by $\mathrm{H} \cdots \mathrm{O}$ distances of $1.018 \AA$ (between the migrating proton and the oxygen of the sulfuric acid) and $1.750 \AA$ (between the migrating proton and the oxygen of the oxime). Thus, the sulfuric acid catalyst provides electrostatic stabilization to the migrating proton. This electrostatic stabilization reduces the barrier for the proton transfer by $91.3 \mathrm{~kJ} \mathrm{~mol}^{-1}$, relative to the uncatalyzed reaction barrier. However, the barrier for the catalyzed proton transfer is still relatively high $\Delta G^{\sharp}{ }_{298}$ (TS1 TS- $_{3-}$ membered) $=153.3 \mathrm{~kJ} \mathrm{~mol}^{-1}$ (Figure 7), ostensibly due to the large strain energy in the cyclic threemembered-ring TS (Figure 6). This reaction barrier is still significantly higher than the reaction barriers for the ensuing steps, namely: $\Delta G^{\ddagger} 298($ TS2 $)=115.9 \mathrm{~kJ} \mathrm{~mol}^{-1}$ and $\Delta G^{\sharp} 298($ TS3 $)=69.3 \mathrm{~kJ}$ $\mathrm{mol}^{-1}$. Thus, similarly to the uncatalyzed case, in this catalytic mechanism the 1,2-proton shift is 
the step with the highest Gibbs-free activation energy. These results are consistent with the results obtained previously for a related system at the MP2/6-311G(d,p) level of theory. ${ }^{11}$

It was recently found that sulfuric acid can efficiently catalyze 1,2- and 1,3-proton shifts by alleviating the strain energy involved in highly strained three- and four-membered-ring TSs, respectively. ${ }^{14,15}$ In particular, a double proton shift between the $\mathrm{H}_{2} \mathrm{SO}_{4}$ catalyst and the substrate leads to an energetically low-lying TS (Figure 3b). The sulfuric acid catalyst reduces the strain energy involved in the uncatalyzed TS by converting a three-membered-ring TS (TS1 3-membered) $_{\text {) }}$ to a seven-membered-ring TS (TS1 ${ }_{7 \text {-membered, Figures } 3 \text { and 6). Indeed, we find that TS1 }}$ 7-membered $_{\text {}}$

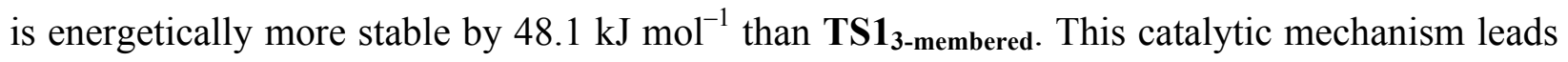
to a reaction barrier for 1,2-proton shift of $\Delta G^{\ddagger} 298\left(\mathbf{T S 1}_{7 \text {-membered }}\right)=105.2 \mathrm{~kJ} \mathrm{~mol}^{-1}$. In this situation, the following rearrangement/dehydration step becomes the step with the highest Gibbsfree activation energy, with a barrier of $115.9 \mathrm{~kJ} \mathrm{~mol}^{-1}$. It should be pointed out that the involvement of an additional $\mathrm{H}_{2} \mathrm{SO}_{4}$ molecule in the catalytic mechanism is expected to further reduce the barrier for the 1,2-proton shift on the electronic energy surface. However, on the Gibbs free-energy surface the reduction in the reaction barrier is expected to be much smaller due to entropic effects. ${ }^{24}$ We note that our theoretical results are consistent with experimental ${ }^{12} \mathrm{C} /{ }^{14} \mathrm{C}$ kinetic isotope effect measurements for a related acetophenone oxime substrate, which indicate that the rearrangement/dehydration step is the RDS. ${ }^{18}$

\section{Conclusions}

We use the high-level G4 composite ab initio procedure to investigate the uncatalyzed and $\mathrm{H}_{2} \mathrm{SO}_{4}$-catalyzed Beckman rearrangement reaction. Our results for the uncatalyzed reaction show that the initial 1,2-proton transfer step is clearly the rate-determining step for the entire process. In particular, at the $\operatorname{SMD}\left(\mathrm{H}_{2} \mathrm{SO}_{4}\right)$-G4 level we obtain a reaction barrier of $\Delta G^{\ddagger}{ }_{298}=$ $244.6 \mathrm{~kJ} \mathrm{~mol}^{-1}$ for this step. The high activation energy for this step is largely due to the highly strained three-membered ring involved in the uncatalyzed TS for the proton shift. The reaction barrier for the 1,2-proton transfer step is higher by at least $120 \mathrm{~kJ} \mathrm{~mol}^{-1}$ than the reaction barriers for the succeeding steps. These results are in qualitative agreement with previous theoretical investigations. $^{10,11}$ These studies also suggested that the 1,2-proton transfer can be catalyzed by an $\mathrm{H}_{2} \mathrm{SO}_{4}$ catalyst. ${ }^{11}$ In particular, it was proposed that the $\mathrm{H}_{2} \mathrm{SO}_{4}$ catalyst provides electrostatic stabilization to the migrating proton. In accordance with these results, we find that this 
electrostatic stabilization significantly reduces the barrier for the proton transfer (namely, by 91.3 $\mathrm{kJ} \mathrm{mol}^{-1}$ at the $\operatorname{SMD}\left(\mathrm{H}_{2} \mathrm{SO}_{4}\right)$-G4 level). In this catalytic mechanism, the barrier for the proton transfer $\left(\Delta G^{\ddagger} 298=153.3 \mathrm{~kJ} \mathrm{~mol}^{-1}\right)$ is still significantly higher than the reaction barriers for the ensuing steps. Thus, similarly to the uncatalyzed reaction, the 1,2-proton shift should be the RDS for the entire process.

We proceed to consider an alternative catalytic mechanism in which sulfuric acid catalyzes the 1,2-proton transfer by serving as a proton-transfer bridge between the neighbouring 1,2 atoms. In this mechanism the $\mathrm{H}_{2} \mathrm{SO}_{4}$ catalyst reduces the strain energy involved in the TS by converting the three-membered-ring TS into a seven-membered-ring TS. We find that this catalytic mechanism is more effective than the previously proposed mechanism. Namely, the barrier for the proton transfer is reduced by $139.4 \mathrm{~kJ} \mathrm{~mol}^{-1}$ at the $\mathrm{SMD}\left(\mathrm{H}_{2} \mathrm{SO}_{4}\right)$-G4 level (cf. to a barrier reduction of $91.3 \mathrm{~kJ} \mathrm{~mol}^{-1}$ via the competing mechanism). In this situation, the following rearrangement/dehydration step has a higher Gibbs-free activation energy.

\section{Supplementary data}

$\operatorname{SMD}\left(\mathrm{H}_{2} \mathrm{SO}_{4}\right)-\mathrm{G} 4$ Electronic energies $\left(\Delta E_{e}\right)$ and enthalpies at $298 \mathrm{~K}\left(\Delta H_{298}\right)$ for the local minima and transition structures located for the uncatalyzed BR reaction (Table $\mathrm{S} 1$ ); $\mathrm{SMD}\left(\mathrm{H}_{2} \mathrm{SO}_{4}\right)$-G4 $\Delta H_{298}$ values for the local minima and transition structures located for the 1,2proton shift of the BR reaction catalysed by $\mathrm{H}_{2} \mathrm{SO}_{4}$ (Table S2); B3LYP/6-31G(2df,p) optimized geometries for all the local minima and transition structures considered in the present work (Table S3); Comparison between the Gibbs-free energy surfaces for the uncatalyzed BR reaction in aqueous solution and in concentrated sulfuric acid (Figure S1).

\section{Corresponding author}

*E-Mail: amir.karton@uwa.edu.au

\section{Acknowledgments}

This research was undertaken with the assistance of resources from the National Computational Infrastructure (NCI), which is supported by the Australian Government. We gratefully acknowledge the system administration support provided by the Faculty of Science at the University of Western Australia to the Linux cluster of the Karton group, the provision of an 
Australian Postgraduate Award (to L-J.Y.), and an Australian Research Council (ARC) Discovery Early Career Researcher Award (to A.K., project number: DE140100311).

\section{References}

1. E. Beckmann, Zur Kenntniss der Isonitrosoverbindungen, Berichte der deutschen chemischen 1886, 19, 988.

2. T. A. D. Holth, O. E. Hutt, G. I. Georg. Beckmann Rearrangements and Fragmentations in Organic Synthesis, in Molecular Rearrangements in Organic Synthesis (ed C. M. Rojas), John Wiley \& Sons, Inc, Hoboken, NJ, USA (2015).

3. R. E. Gawley, Beckmann Reactions: Rearrangements, Elimination-Additions, Fragmentations, and Rearrangement-Cyclizations, Org. React. 1988, 35, 1 (and references therein).

4. M. B. Smith, J. March, In Advanced Organic Chemistry, 5th ed.; John Wiley \& Sons: New York, 2001; pp 1415 (and references therein).

5. K. Wessermel, H.-J. Arpe, Industrial Organic Chemistry, 4th ed.; Wiley-VCH: Weinheim, Germany, 2003; pp 239-266.

6. V. D. Luedeke, In Encyclopedia of Chemical Processing and Design; Mcketta, J. J., Ed.; Marcel Dekker: New York, 1978; pp 72-95.

7. M. Ghiacia, H. Aghaeia, M. Oroojenia, B. Aghabararia, V. Rivesb, M.A. Vicenteb, I. Sobradosc, J. Sanzc., Synthesis of paracetamol by liquid phase Beckmann rearrangement of 4-hydroxyacetophenone oxime over H3PO4/Al-MCM-41, Catal. Commun. 2009, 10, 1486.

8. M. T. Nguyen, L. G. Vanquickenborne, Mechanism of the Beckmann Rearrangement of Formaldehyde Oxime and Formaldehyde Hydrazone in the Gas Phase, J. Chem. Soc., Perkin Trans. 2 1993, 10, 1969.

9. M. T. Nguyen, G. Raspoet, L. G. Vanquickenborne, Important role of the Beckmann rearrangement in the gas phase chemistry of protonated formaldehyde oximes and their $\left[\mathrm{CH}_{4} \mathrm{NO}\right]^{+}$isomers, J. Chem. Soc., Perkin Trans. 2 1995, 9, 1791.

10. M. T. Nguyen, G. Raspoet, L. G. Vanquickenborne, A New Look at the Classical Beckmann Rearrangement: A Strong Case of Active Solvent Effect, J. Am. Chem. Soc. 1997, 119, 2552. 
11. M. T. Nguyen, G. Raspoet, L. G. Vanquickenborne, Mechanism of the Beckmann rearrangement in sulfuric acid solution, J. Chem. Soc., Perkin Trans. 2 1997, 4, 821.

12. S. N. Yamabe, Is the Beckmann Rearrangement a Concerted or Stepwise Reaction? A Computational Study, J. Org. Chem. 2005, 70, 10638.

13. S. Miertus, E. Scrocco, J. Tomasi, Electrostatic interaction of a solute with a continuum. A direct utilizaion of $\mathrm{AB}$ initio molecular potentials for the prevision of solvent effects, Chem. Phys. 1981, 55, 117.

14. A. Karton, Inorganic acid-catalyzed tautomerization of vinyl alcohol to acetaldehyde, Chem. Phys. Lett. 2014, 592, 330.

15. R. J. Buszek, A. Sinha, J. S. Francisco, The Isomerization of Methoxy Radical: Intramolecular Hydrogen Atom Transfer Mediated through Acid Catalysis, J. Am. Chem. Soc. 2011, 133, 2013.

16. G. da Silva, Carboxylic Acid Catalyzed Keto-Enol Tautomerizations in the Gas Phase, Angew. Chem. Int. Ed. 2010, 49, 7523.

17. L. A. Curtiss, P. C. Redfern, K. Raghavachari, Gaussian-4 theory, J. Chem. Phys. 2007, $126,084108$.

18. S.-G. Kim, T. Kawakami, T. Ando, Y. Yukawa, The Beckmann Rearrangement in Concentrated Sulfuric Acid. Studies by Means of NMR and Kinetic Isotope Effect, Bull. Chem. Soc. Japan 1979, 52, 1115.

19. L. A. Curtiss, P. C. Redfern, K. Raghavachari, Gn theory, WIREs Comput. Mol. Sci. 2011, 1,810 .

20. A. Karton, S. Daon, J. M. L. Martin, W4-11: A high-confidence dataset for computational thermochemistry derived from W4 ab initio data, Chem. Phys. Lett. 2011, $510,165$.

21. A. Karton, A computational chemist's guide to accurate thermochemistry for organic molecules, WIREs Comput. Mol. Sci. 2016, 6, 292.

22. L. A. Curtiss, P. C. Redfern, K. Raghavachari, Assessment of Gaussian-3 and densityfunctional theories on the G3/05 test set of experimental energies, J. Chem. Phys. 2005, $123,124107$.

23. L. A. Curtiss, P. C. Redfern, K. Raghavachari, Assessment of Gaussian-4 theory for energy barriers, Chem. Phys. Lett. 2010, 499, 168. 
24. A. Karton, R. J. O'Reilly, L. Radom, Assessment of theoretical procedures for calculating barrier heights for a diverse set of water-catalyzed proton-transfer reactions, J. Phys. Chem. A 2012, 116, 4211.

25. A. Karton, L. Goerigk, Accurate reaction barrier heights of pericyclic reactions: surprisingly large deviations for the CBS-QB3 composite method and their consequences in DFT benchmark studies, J. Comp. Chem. 2015, 36, 622.

26. L.-J. Yu, F. Sarrami, R. J. O'Reilly, Reaction barrier heights for cycloreversion of heterocyclic rings: An Achilles' heel for DFT and standard ab initio procedures, A. Karton, Chem. Phys. 2015, 458, 1.

27. C. Gonzalez, H. B. Schlegel, An improved algorithm for reaction path following, J. Chem. Phys. 1989, 90, 2154.

28. C. Gonzalez, H. B. Schlegel, Reaction Path Following in Mass-Weighted Internal Coordinates, J. Phys. Chem. 1990, 94, 5523.

29. A. V. Marenich, C. J. Cramer, D. G. Truhlar, Universal Solvation Model Based on Solute Electron Density and on a Continuum Model of the Solvent Defined by the Bulk Dielectric Constant and Atomic Surface Tensions, J. Phys. Chem. B 2009, 113, 6378.

30. Gaussian 09, Revision E.01, M. J. Frisch, G. W. Trucks, H. B. Schlegel, G. E. Scuseria, M. A. Robb, J. R. Cheeseman, G. Scalmani, V. Barone, B. Mennucci, G. A. Petersson, H. Nakatsuji, M. Caricato, X. Li, H. P. Hratchian, A. F. Izmaylov, J. Bloino, G. Zheng, J. L. Sonnenberg, M. Hada, M. Ehara, K. Toyota, R. Fukuda, J. Hasegawa, M. Ishida, T. Nakajima, Y. Honda, O. Kitao, H. Nakai, T. Vreven, J. A. Montgomery, Jr., J. E. Peralta, F. Ogliaro, M. Bearpark, J. J. Heyd, E. Brothers, K. N. Kudin, V. N. Staroverov, R. Kobayashi, J. Normand, K. Raghavachari, A. Rendell, J. C. Burant, S. S. Iyengar, J. Tomasi, M. Cossi, N. Rega, J. M. Millam, M. Klene, J. E. Knox, J. B. Cross, V. Bakken, C. Adamo, J. Jaramillo, R. Gomperts, R. E. Stratmann, O. Yazyev, A. J. Austin, R. Cammi, C. Pomelli, J. W. Ochterski, R. L. Martin, K. Morokuma, V. G. Zakrzewski, G. A. Voth, P. Salvador, J. J. Dannenberg, S. Dapprich, A. D. Daniels, Ö. Farkas, J. B. Foresman, J. V. Ortiz, J. Cioslowski, and D. J. Fox, Gaussian, Inc., Wallingford CT, 2009.

31. Note that on the $\mathrm{SMD}\left(\mathrm{H}_{2} \mathrm{SO}_{4}\right)-\mathrm{G} 4$ Gibbs-free energy surface, the intermediate (Int1) lies $9.5 \mathrm{~kJ} \mathrm{~mol}^{-1}$ above the transition structure (TS1). This anomaly in the Gibbs-free energy 
surface is a result of the zero-point vibrational energy, enthalpic, and entropic corrections, which are not taken into account in the geometry optimizations. On the $\operatorname{SMD}\left(\mathrm{H}_{2} \mathrm{SO}_{4}\right)$-G4 electronic surface Int1 lies $6.8 \mathrm{~kJ} \mathrm{~mol}^{-1}$ below TS1 (see Table S1 of the Supporting Information for further details). 